\title{
SOBRE A NECESSIDADE/UTILIDADE DA FLEXIBILIZAÇÃO PROCEDIMENTAL PELO JUIZ NO SISTEMA PROCESSUAL BRASILEIRO: UMA ANÁLISE NECESSÁRIA
}

\section{ON THE NEED / UTILITY OF FLEXIBILIZATION PROCEDURAL BY JUDGE OF PROCEDURE SYSTEM IN BRAZIL : AN ANALYSIS REQUIRED}

Bruna Rocha Passos ${ }^{1}$

\begin{abstract}
RESUMO
O presente estudo aborda o fenômeno da flexibilização procedimental, uma das inovações previstas no Novo Código de Processo Civil, introduzido no Brasil pela Lei n. ${ }^{\circ}$ 13.105/2015. O estudo se inicia com a apresentação dos modelos de sistemas procedimentais e suas especificidades. Parte-se, em seguida, para o estudo dos modelos de flexibilização procedimental existentes nos demais ordenamentos jurídicos, com especial análise das principais especificidades dos modelos de flexibilização adotados por Inglaterra, EUA e Portugal. Em seguida, faz-se a análise da flexibilização procedimental pelo juiz no Brasil, desde o projeto inicialmente apresentado na Câmara dos Deputados, até a versão final definida na Lei n. ${ }^{\circ} 13.105 / 2015$. Por fim, é realizada uma análise crítica do instituto tendo em vista o Código de Processo Civil de 1973, a finalidade do instituto de imprimir maior celeridade aos processos, em cotejo com as questões que tornam o sistema processual brasileiro moroso. O intento deste trabalho, portanto, compreende o delineamento da flexibilização procedimental na experiência estrangeira e na perspectiva nacional. Para tanto, foi empregado o método dedutivo-comparativo.
\end{abstract}

Palavras-chave: Flexibilização procedimental, Gestão processual, Poderes do juiz, Lei n. $13.105 / 2015$

\begin{abstract}
This study addresses the phenomenon of procedural flexibility, one of the innovations provided for in the New Civil Procedure Code, introduced in Brazil by Law No. 13,105/2015. The study begins with the presentation of models of procedural systems and their characteristics. Breaks, then to the study of existing procedural flexibility models in other jurisdictions, with a special analysis of the main specificities of flexible models adopted by England, USA and Portugal. Then, it is the analysis of procedural flexibility by the judge in Brazil, from design first introduced in the House until the final version defined in Law No. 13,105 / 2015. Finally, we performed a critical analysis of the institute in view of the Civil Procedure Code 1973, the purpose of the institute to expedite the process in comparison with the issues that make the lengthy Brazilian legal system. The intent of this study, therefore, includes the design of procedural flexibility in foreign experience and national perspective. For this, we used the deductive-comparative method.
\end{abstract}

Keywords: Procedural flexibility, Procedural management, Prerrogatives of the judge, Law n . 13.105 / 2015

\footnotetext{
1 Mestranda pela Universidade Federal do Espírito Santo - UFES, Espírito Santo, (Brasil). E-mail: brunapassos2005@yahoo.com.br
} 


\section{INTRODUÇÃO}

O tema "flexibilização procedimental" além de ser novo no ordenamento jurídico brasileiro, traz à tona o questionamento quanto à necessidade-utilidade de um instituto que concede aos juízes um elevado grau de discricionariedade em determinadas situações de modo a adequar os procedimentos previstos de forma taxativa no CPC às especificidades do caso concreto, com a finalidade de oferecer uma resposta imediata às novas questões que colocadas em julgamento.

Fato é que as mutações verificadas na realidade social não são acompanhadas de modo imediato pelas regras de direito, cuja alteração demanda tempo por ser um processo de alteração burocrático. Os conflitos sociais, por outro lado, exigem do judiciário um dinamismo prático como critério de efetividade do direito na prestação jurisdicional.

Essa relação entre a multiplicidade das relações sociais e seu dinamismo ao lado da necessidade de efetiva e tempestiva solução das controvérsias decorrentes dessas novas relações põe em xeque o modelo de processo civil tradicional, em especial no que tange à necessidade de respostas mais céleres e eficientes em matéria de pacificação social.

É certo que há autonomia entre o direito processual civil e o direito material que se pretende tutelar. No entanto, o direito processual, como instrumento de resolução de controvérsia, é diretamente influenciado por essa exigência social de celeridade e eficiência.

Por tal razão, as técnicas processuais vêm passando por importantes alterações, a exemplo da lei n. ${ }^{\circ} 13.105 / 2015$, que introduz no ordenamento jurídico brasileiro o novo Código de Processo Civil, e que foi resultado dessa exigência social de revisão das regras existentes para que fossem adequadas a uma realidade multifacetada e extremamente dinâmica, conforme declarado na exposição de motivos do Anteprojeto do novo Código de Processo Civil.

O novo Código de Processo Civil tem o potencial de gerar um processo mais célere, mais justo, porque mais rente às necessidades sociais e muito menos complexo. 
Nessa fase de transformação das regras processuais, as opiniões se dividem entre a necessidade de segurança jurídica e observância ao devido processo legal substancial e os anseios por um processo que garanta efetividade na prestação jurisdicional, e a duração razoável do processo.

Se por um lado temos a necessidade de responder às questões sociais com a maior eficiência e no menor tempo possível, sob outra perspectiva, as formalidades e os procedimentos existentes, longe de pretender funcionar como entraves na prestação jurisdicional, antes atuam como garantias decorrentes do devido processo legal constitucional, em favor do cidadão, que tem garantida a previsibilidade dos procedimentos e a segurança de não ser surpreendido com atuações eivadas de discricionariedade ou mesmo de personalismos.

É nesse contexto que a inovação da flexibilização procedimental, incluída no novo CPC, surge como alternativa para as situações em que no caso concreto, a solução procedimental existente se demonstre insuficiente ou inapropriada para solucionar o conflito objeto de questionamento.

O objetivo do presente artigo, longe de pretender esgotar o tema, é apresentar os modelos de flexibilização existentes no mundo, as características próprias de cada experiência, para então expor o modelo de flexibilização criado pelo novo CPC. Por fim, far-se-á uma análise crítica do novel instituto processual sob a ótica da segurança jurídica e dos anseios de celeridade/efetividade sobre a necessidade do instituto no Brasil, tendo em vista as características próprias do ordenamento jurídico doméstico.

Para alcançar os objetivos propostos, adotamos um método dedutivo, pautado por um estudo de analítico-sintético dos materiais bibliográficos e documentais reunidos, os quais foram analisados à luz dos enunciados normativos constantes nos diplomas jurídicos vigentes no Direito brasileiro, bem como da opinião de estudiosos acerca do tema escolhido. 


\section{MODELOS PROCEDIMENTAIS}

O modelo procedimental de um sistema varia de acordo com a maior ou menor flexibilidade na aplicação das regras procedimentais no caso concreto e se há a possibilidade de as partes e os Juízes modificarem essas regras, alterando o modelo procedimental préestabelecido de modo a se adequar às especificidades do caso concreto, ou a possibilidade de se afastar a preclusão temporal de modo à retornar às fases já superadas (GAJARDONI, 2008, p. 100-103).

De acordo com Gajardoni (2008, p. 93), em relação ao procedimento, dois sistemas processuais são apontados pela doutrina: a) sistema da legalidade das formas procedimentais; b) sistema da liberdade de formas procedimentais.

No primeiro sistema procedimental, o lugar e o tempo da prática de cada ato processual vêm prévia e rigidamente estabelecidos em lei, com a previsão clara de um sistema de nulidades e de preclusões, consequência do não cumprimento dos atos tal como fixado em lei, ou do seu intempestivo cumprimento.

O sistema da legalidade das formas tem a vantagem de garantir a previsibilidade de todos os atos processuais a serem praticados pelos sujeitos do processo, principalmente os atos de competência do Estado-Juiz, o que sem dúvida alguma contribui para uma maior segurança-jurídica, ao permitir de antemão, o controle da marcha processual, inclusive no que tange à possibilidade de aplicação de sanções processuais.

A principal crítica a esse modelo processual é o excesso de burocracia, o formalismo exacerbado, e em muitas ocasiões implica a prática de atos processuais desnecessários ou inadequados à efetiva tutela dos direitos (GAJARDONI, 2008, p. 95).

O sistema da liberdade das formas, por sua vez, não possui uma ordem legal préestabelecida de forma rígida. Pelo contrário, a legislação processual em matéria de procedimento é enxuta. Por tal razão, aos sujeitos processuais (partes e juiz) é conferida uma maior autonomia para a condução do processo. Há um espaço de liberdade para que o juiz decida quanto à conveniência ou não da prática de determinado ato processual, bem como para definir o momento de sua realização. 
O atual Código de Processo Civil, por razões históricas, optou preponderantemente pelo modelo da legalidade das formas. Criado num período ditatorial, a estrita legalidade e a previsibilidade dos atos, do sistema de nulidades e de preclusão na verdade mais representam uma garantia do cidadão contra a ingerência estatal que uma forma de engessamento do procedimento.

As regras de processo civil no Brasil são regras de ordem púbica, que visam garantir a realização do escopo do processo, a pacificação social, por meio da participação ativa e dialética das partes envolvidas.

O legislador do CPC/1973, com a exaustiva disciplina de todos os procedimentos especiais, adequados às especificidades do direito material tutelado, e o estabelecimento de um procedimento comum ordinário, destinado a todos os demais casos que não se enquadrassem nas regras dos procedimentos especiais, teve como objetivo distribuir de modo equitativo os ônus processuais, de tal forma que a verdade processual fosse construída de forma discursiva, com a garantia do contraditório e de participação colaborativa e equânime das partes no processo.

Embora existam interesses particulares em litígio, o escopo processual é o interesse público na solução democrática dos conflitos sociais. Por tal razão, a doutrina afirma que as normas de direito processual são de ordem pública e cogentes, especialmente no que se refere à forma do ato ou aos prazos, sem espaço para disposição destas normas ao interesse das partes, senão nas situações em que o legislador assim autorize (GAJARDONI, 2008, p. 97).

A Emenda Constitucional $n^{\circ} 45$ de 2004, introduziu no rol dos direitos fundamentais a duração razoável do processo e a celeridade (artigo $5^{\circ}$, inciso LXXVIII). A leitura constitucional das regras de processo civil exige o uso racional dos instrumentos processuais pelas partes e pelo juízo. Há uma tendência muito forte no sentido de desburocratizar o processo, de forma a torná-lo mais dinâmico e mais próximo de sua finalidade.

No sistema processual adotado pelo Código de Processo Civil de 1973 não há flexibilidade procedimental. A lei disciplinou de forma exaustiva os procedimentos especiais existentes, em atenção às especificidades do direito material a ser tutelado e colocou o procedimento comum ordinário como regra geral de atuação (WAMBIER, 2013). 
Portanto, não é difícil concluir que no ordenamento jurídico brasileiro, até a publicação da Lei n. ${ }^{\circ}$ 13.105/2015 não havia discricionariedade na escolha dos procedimentos. Do mesmo modo, não era possível mesclar os procedimentos existentes, de modo a criar novas hipóteses. Também não era possível retornar às fases processuais já superadas, afastando-se preclusões, nem se admitia flexibilizar os prazos, senão nas hipóteses taxativamente previstas em lei. Nada havia, no processo de conhecimento, que pudesse sugerir qualquer tipo de adaptação do procedimento.

Na sistemática do CPC de 1973, quando se tratava de matéria que não se enquadrava em qualquer dos procedimentos especiais, o procedimento comum era o adotado, não havendo margem para qualquer alteração.

Na contramão da sistemática de rigidez procedimental do CPC de 1973, a Lei n. ${ }^{\circ} 13.105 / 2015$ traz a novidade da flexibilização procedimental na esperança de imputar ao sistema maior celeridade e eficiência na condução do processo.

Para muitos, o atual modelo procedimental não seria suficiente para atender com eficiência a todas as demandas postas em análise. Por isso, ganha fôlego a ideia de alterar o sistema processual brasileiro para que os procedimentos existentes sejam flexibilizados de modo a se adequar às especificidades do caso concreto.

Esse modelo de gestão processual é adotado de diversas formas ao redor do mundo. Como principais modelos, é possível citar o modelo português, o britânico, e o norteamericano.

Antes de apresentarmos as alterações legislativas no ordenamento jurídico brasileiro, pontuaremos as principais nuances dos modelos de flexibilização procedimental existentes nos demais ordenamentos jurídicos, com destaque para suas especificidades. 


\section{MODELOS DE FLEXIBILIZAÇÃO PROCEDIMENTAL}

\subsection{MODELO INGLÊS}

$\mathrm{Na}$ Inglaterra, de tradição processual vinculada ao adversarial system (GAJARDONI, 2008, p. 130), e, portanto, caracterizado por uma ampla participação das partes na determinação do procedimento e na instrução probatória, atrelado a uma atuação do Juiz mais inerte e sujeito à vontade dos particulares, também houve significativa mudança na postura do papel atribuído ao juiz.

$\mathrm{Na}$ Inglaterra dos anos 90, os litígios em matéria civil eram regulados por duas fontes legislativas de direito processual, quais sejam, RSC (Rules of the Supreme Court), que lidavam com questões referentes à High Courte a Court of Appel, e o CCR (County Court Rules). O sistema adotado conferia ao juiz um papel passivo, de atuação apenas mediante provocação das partes. Às partes, por outro lado, competia a gestão dos processos (ALMEIDA, 2011, p. 295).

A ampla liberdade outrora outorgada às partes na condução do procedimento no sistema inglês teve como consequência uma maior lentidão na resolução das controvérsias e a elevação dos custos da justiça civil inglesa, que comprometiam significativamente o direito de acesso à justiça. Por tal razão, em 1999 foram implementadas inúmeras alterações, sendo instituída uma espécie de Código de Processo Civil Inglês (MOREIRA, 1999, p. 87-89).

Uma das principais alterações verificadas no sistema inglês foi o deslocamento da gestão processual das partes para o juiz, inclusive em matéria probatória. Com a promulgação das Rules of Civil Procedure, numerosos poderes foram outorgados ao juiz inglês. Esses poderes de gestão, alguns nomeados de case management, autoriza o juiz a conduzir a marcha processual de forma a se alcançar a justiça substancial.

O professor Diogo Assumpção Rezende de Almeida, em estudo intitulado “O case management Inglês: um sistema maduro?”, aponta o rol exemplificativo de poderes que a regra 1.4 do CPR atribui ao juiz. São eles:

(i) estimular as partes a cooperarem entre si e na condução do processo;

(ii) identificar as questões a serem dirimidas no início do procedimento;

(iii) avaliar de imediato quais questões necessitam de dilação probatória e submissão ao trial e quais podem ser superadas sumariamente; 
(iv) decidir a ordem em que as questões serão solucionadas;

(v) estimular o uso de Alternative Dispute Resolution (ADR), ou Métodos Alternativos de Solução de Conflitos, se o tribunal considerá-lo adequado ao caso, e facilitar a utilização do método alternativo;

(vi) auxiliar as partes na realização de acordos totais ou parciais;

(vii) estabelecer calendários ou controlar o progresso do procedimento;

(viii) considerar se os prováveis benefícios da prática de determinado ato justificam o custo necessário;

(ix) lidar com o maior número possível de aspectos do caso na mesma oportunidade;

(x) lidar com os casos sem que as partes tenham de comparecer ao tribunal;

(xi) utilizar-se da tecnologia; e

(xii) dar diretrizes capazes de fazer com que o trial se dê de forma rápida e eficiente.137 No corpo das CPR são encontrados outros atos, cuja prática o legislador espera do juiz, que serão analisados separadamente mais adiante.(2011, p. 296-297).

Ainda segundo o referido autor, no que se refere ao poder de gestão dos juízes no sistema inglês:

A Parte 3 das CPR contém a principal fonte de poderes do juiz inglês para gerir o processo. Na regra 3.1(2), estão elencados os seguintes: (i) estender ou diminuir prazos contidos em quaisquer das normas, diretrizes ou em decisões judiciais prévias, ainda que o requerimento de extensão tenha sido feito após o prazo; (ii) retardar ou antecipar uma audiência; (iii) ordenar o comparecimento ao tribunal da parte ou de seu advogado; (iv) determinar a produção de prova por telefone ou pelo uso de qualquer outro método de comunicação oral direta, durante uma audiência; (v) estabelecer que parte das questões ou ações envolvidas no processo, como pedidos contrapostos, sejam apreciadas em procedimentos separados; (vi) suspender total ou parcialmente o processo; (vii) reunir as questões em um único processo; (viii) julgar duas ou mais ações na mesma ocasião; (ix) estabelecer a realização de julgamento separado para qualquer das questões envolvidas no caso; (x) decidir a ordem em que serão apreciadas as questões; (xi) determinar a exclusão de uma questão da apreciação da corte; (xii) julgar determinada ação logo após a apreciação de questão preliminar; (xiii) determinar que qualquer das partes apresentem uma estimativa dos custos que esperam ter com o desenrolar do processo; (xiv) tomar outras decisões necessárias ao objetivo de gerir o caso com vistas ao overridingobjective.(2011, p. 301-302).

Ao lado do incremento dos poderes dos juízes na condução dos processos, verificou-se o abrandamento das características do adversarial system. No Código de Processo Civil inglês os litigantes passam a ter um papel cooperativo na resolução dos litígios, e é estimulado o uso 
racional do processo e a utilização de métodos alternativos para a resolução dos conflitos. Sobre o assunto, discorre Fernando Gajardoni:

Logo na regra n. 1.4.2 da Civil Procedure Rules (CPR), já são apresentados 12 itens para implementação do active case manegement no processo civil inglês, conferindo-se ao magistrado britânico, pois, papel ativo na condução do processo. Desde já se adiante que em linhas gerais o case manegement inglês é semelhante ao norte-americano. Ambos operam na outorga de poderes de direção ao juiz para o alcance de um processo justo, rápido e econômico, bem como incentivam o uso dos meios alternativos de solução de controvérsias. A partir da reforma operada no sistema processual civil inglês, a diferença entre ambos os modelos é a fonte normativa: o case manegement norte-americano, conforme veremos adiante, está fundado em disposições não legais editadas por um centro de acompanhamento do funcionamento das cortes federais (o Federal Judicial Center), enquanto o case manegement inglês tem incidência por força de disposição legal cogente (as Civil Procedure Rules) [...].

Para entoar o escopo geral das CPR de permitir às cortes tratar dos casos individualmente e de forma justa (R.1.1.1), são estabelecidas diretrizes gerenciais para todos os julgadores: (a) identificar as questões envolvidas nos casos; (b) resolver as questões simples rapidamente, e estabelecer parâmetros para a resolução das demais questões; (c) estabelecer cronogramas das providências que serão adotadas no procedimento, inclusive determinando a ordem em que os atos serão praticados e os seus prazos; e (d) controlar o volume de provas, limitando-as ao necessário. (2011, p.693-694).

Gajardoni (2008, p. 140-141) destaca que no CPR há apenas três procedimentos (tracks, procedures, ou courses of actions) para a solução das demandas, disciplinadas com base no valor da causa.

Salvo nas situações expressamente vedadas pelas CPR, as partes e o juiz podem optar por quaisquer destes procedimentos, respeitados alguns aspectos legais que indicam os dados tidos como relevantes para a opção procedimental (matters relevantto allocation to a track), tais como a complexidade dos fatos, ou do direito, o número de litigantes ou sua qualidade especial, os reflexos da decisão para pessoas que não são partes, a complexidade da prova a ser produzida, dentre outros fatores elegidos pela norma processual.

Diogo Assumpção Rezende de Almeida (2011, p. 311) destaca que no case management, o princípio dispositivo ou da inércia da jurisdição é respeitado, mas, uma vez provocado, o juiz passa a ter o poder-dever de levar adiante o processo. Nesse quadro está incluída a possibilidade de serem proferidas decisões de ofício pela corte, sem necessária 
provocação de qualquer das partes ou audiência prévia, consoante preveem as regras 3.3(3) e 3.3(4) das CPR.

Em relação ao êxito da reforma inglesa, destaca Fernando Gajardoni:

A reforma processual civil inglesa, de acordo com fontes do governo britânico, foi considerada exitosa logo após três anos de adoção da CPR. Acompanhamento estatístico da reforma mostrou que o tempo médio de julgamento de um caso nas cortes locais caiu de 639 dias em setembro de 1997 (antes das CPR) para 498 dias em 2000-2001. Revelou, ainda, que o tempo entre a reclamação e a audiência inicial nos juizados de pequenas causas, apesar de aumentar logo após a introdução das CPR, começou a cair a partir de 2002. E que a substituição do primeiro ano de vigência da reforma, de um aumento significativo de casos submetidos aos meios alternativos de solução das controvérsias (ADR), o que está contribuindo para a formação de uma cultura jurídica menos adversarial na Inglaterra e para a diminuição do número de demandas ajuizadas (2008, p. 135).

Como se pode observar, após certo tempo, houve a diminuição da duração dos processos no sistema inglês e a maior utilização dos sistemas alternativos de solução de controvérsias, o que contribui significativamente para a redução do número de demandas judicializadas.

\subsection{MODELO NORTE-AMERICANO}

A reforma do sistema processual americano teve início na década de 70. As cortes federais americanas iniciaram um programa de condução dos processos judiciais individualizadamente, denominado judicial case management (GAJARDONI, 2008, p. 136).

Após notar que a ineficácia do sistema judicial influenciava diretamente na competitividade dos negócios norte-americanos no mercado internacional, foram implementadas inúmeras reformas no sistema processual dos EUA, denominado de Civil Justice Reform Act, de 1990.

O objetivo da reforma processual foi claramente aumentar a produtividade do poder judiciário e reduzir o tempo da demanda. A reforma se desenvolveu basicamente sob dois alicerces: i) a utilização de meios alternativos de solução de controvérsias e ii) a flexibilização judicial do procedimento, de modo que compete às partes em conjunto com os juízes, definir previamente as etapas do procedimento(GAJARDONI, 2008, p. 137). 
Gajardoni (2008, p. 137) destaca que os modelos de case management norte americano possuem as seguintes características comuns: i) envolvimento do magistrado com o caso desde o início do processo; ii) participação ativa do julgador na investigação da verdade; iii) elaboração de planos e cronogramas de desenvolvimento de cada caso; iv) treinamento dos juízes com técnicas de gerenciamento de casos; v) planejamento de prazos e procedimentos diferenciados de acordo com a complexidade do caso.

Ainda de acordo com o referido autor, o sistema norte americano tem um órgão central, denominado Federal Judicial Center, que sistematiza e fiscaliza as práticas judiciais, ministra treinamentos aos juízes, e faz o intercâmbio entre as diversas cortes federais.

A experiência dos EUA não se limitou à alteração legislativa, mas construiu-se uma estrutura material para as cortes, que dispõem de recursos humanos devidamente treinados a operar em cooperação com o Poder Judiciário. Ao magistrado são conferidos amplos poderes na condução do processo, desvinculado de modelos rigidamente estabelecidos em lei, o chamado juiz gerencial, em substituição às partes.

Essa busca incessante por resultados e por uma maior produtividade por parte dos juízes pode ter como consequência o comprometimento da prestação jurisdicional. Trícia Navarro faz importante observação em relação ao excesso de poderes conferidos ao juiz no modelo norte americano. Dada a importância das observações, passamos à transcrição:

Essa responsabilidade gerencial dá aos juízes grande poder. Eles trabalham longe da publicidade e sem registro, como também sem nenhuma obrigação escrita, motivação e fora do alcance recursal. É uma nova forma de "ativismo judicial", uma atitude que comumente atrai críticas substanciais. Judith Resnik alerta que os juízes gerenciais ensinam outros juízes a valorizar estatísticas, como o número de casos distribuídos, mais do que a qualidade de sua distribuição. (2010, p. 140).

Os juízes norte americanos no case management gerenciam o processo sem regras préestabelecidas, muitas de suas decisões não são submetidas a recursos, e há um enorme incentivo ao uso de meios alternativos de solução de controvérsias.

De fato, se verifica um excesso de poderes nas mãos dos juízes, que, pressionados por resultados cada vez melhores, podem colocar em risco a qualidade da prestação jurisdicional. A pressão por maiores resultados no menor tempo possível pode comprometer substancialmente a participação das partes em contraditório, a instrução probatória. Por outro 
lado, a inexistência de regras pré-estabelecidas tem como risco, a impossibilidade de controle das partes sobre os atos praticados pelos magistrados.

\subsection{MODELO PORTUGUÊS}

Seguindo as diretrizes da União Europeia, em 1993 Portugal iniciou uma reformulação de suas normas processuais, com o objetivo de concretizar o direito de acesso à justiça, com decisões proferidas num prazo razoável, por meio de um processo dialético que garanta a ampla participação das partes em contraditório (art. $2^{\circ}$ da Lei n. ${ }^{\circ} 33 / 95$ ).

Em Portugal, desde a reforma do CPC de 1995 (Decreto-lei n. 329-A/95), foi instituído o art. 265-A, que trata do princípio da adequação formal, contendo disposições bem semelhantes ao que se pretendia instituir por meio do Projeto do novo CPC brasileiro, ou seja, conferindo amplo poder de gestão processual ao juiz português para a promoção de adaptações procedimentais. O art. 265-A do Código de Processo Civil Português assim dispõe:

Quando a tramitação processual prevista na lei não se adequar às especificidades da causa, deve o juiz oficiosamente, ouvidas as partes, determinar a prática dos actos que melhor se ajustem ao fim do processo, bem como as necessárias adaptações.

Esta redação, resultante do D.L. 180/96, substituiu a do D.L. 329-A/95, de 12 de Dezembro, que era mais rígida na solução desenhada:

1 - Quando a tramitação processual prevista na lei não se adequar às especificidades da causa, deve o juiz, oficiosamente e com o acordo das partes, adaptar o processado.

2 - Na execução da atribuição referida no número anterior, determina o juiz a realização dos actos que melhor se adequem ao apuramento da verdade e acerto da decisão, prescindindo dos que se revelem manifestamente inidóneos para o fim do processo."Dezembro, que era mais rígida na solução desenhada:

Sobre o novo modelo processual português, afirma Fernando Gajardoni:

Com efeito, o novo princípio da adequação formal vem romper com o apertado regime da legalidade das formas processuais. Através dele, visa-se remover um obstáculo ao acesso à justiça em obediência à natureza instrumental da forma do processo; se a tramitação prevista na lei não se adequar ao fim do processo. Conferem-se, então, os correspondentes poderes ao juiz para adaptar a sequência processual às especificidades da causa 
apresentada em juízo, reordenando os atos processuais a serem praticados no iter, inclusive com a determinação da prática de ato não previsto ou a dispensa de ato inútil previsto, ou ainda com a alteração da ordem dos atos abstratamente disciplinados em lei. [...]

Acrescente-se a isso, ainda, o fato de que não há antecedentes históricos, tampouco paralelos em direito comparado, a facilitar a interpretação do novel princípio na extensão em que foi contemplado pelo CPC português.

Por isso, a doutrina portuguesa vem se esforçando para traçar limites à aplicação do dispositivo, bem como obviar as hipóteses práticas de sua utilização. (2008, p. 141).

Em 2006 foi instituído o chamado Regime Processual Civil Experimental, que explicitou o escopo do princípio da adequação formal e reforçou os poderes do magistrado de condução do processo de forma ágil e menos burocrática. $\mathrm{O}$ escopo do princípio da adequação formal vem exposto no preâmbulo do Decreto-Lei n. ${ }^{\circ}$ 108/2006:

Do dever de gestão processual agora estabelecido decorrem, para o juiz, os imperativos de adoptar a tramitação processual adequada às especificidades da causa e o conteúdo e a forma dos actos ao fim que visam atingir e de garantir que não são praticados actos inúteis, tendo ainda de fazer uso dos mecanismos de agilização processual que a lei estabelece.

Manifestação deste dever é a faculdade concedida ao juiz de, uma vez concluso o processo para saneamento, conhecer das excepções dilatórias e nulidades processuais suscitadas pelas partes ou que deva apreciar oficiosamente, julgar de imediato a causa se o estado do processo o permitir, convocar a audiência preliminar para selecção da matéria de facto ou exercício do contraditório ou designar o dia para a audiência de julgamento. $\mathrm{O}$ conjunto de actos previstos neste artigo (art. $10^{\circ}$ deste diploma) não é, sequer, taxativo, podendo o magistrado praticar no processo qualquer acto ou diligência que lhe pareça mais adequado. Deve, pois, dirigir activa e dinamicamente o processo, tendo em vista a sua rápida e justa resolução e a melhor forma de organizar o seu trabalho.

O Regime Processual Civil Experimental, em reforço à reforma de 1995, implementou um regime processual civil mais simples e flexível, tendo no juiz a figura central na condução do processo, sem olvidar do papel dos sujeitos em contraditório, de modo cooperativo.

Dentre as características que o representam estão a atribuição de poderes efetivos ao juiz, que dirige o processo e determina o procedimento a ser adotado. Após ouvir as partes, o juiz deve adotar mecanismos de simplificação sem deixar de garantir a igualdade das partes e o contraditório, para proporcionar a composição do litígio em prazo razoável (CABRAL, 2010, p. 143). 
O princípio da adequação formal português rompe com o regime da legalidade das formas processuais para prestigiar a substância. Tende a desestimular o uso de faculdades dilatórias pelas partes, evitando-se, por consequência, o uso do processo para outros fins que não a efetiva solução do litígio.

O objetivo perseguido pelo princípio da adequação formal é garantir o acesso à justiça de modo que regras rigorosas de natureza instrumental não sejam empecilho à efetivação de direitos em juízo. Há uma visão do processo através de sua natureza instrumental e não como um fim em si mesmo. Se no caso concreto o juiz verifica que a sequencia procedimental prevista em lei não atende às especificidades da causa no que tange ao direito material envolvido, deve adequá-la de modo a atender com eficiência aos escopos da jurisdição.

Dentre os instrumentos utilizados pelo sistema processual civil português para atingir tal escopo estão a simplificação das peças processuais, o indeferimento de meios de provas inadequados, a aplicação de penalidades sancionatórias por abusos cometidos no uso de recursos manifestamente improcedentes e a aplicação da multa por litigância de má-fé, por violação dos deveres de boa-fé, com aplicação de multa superior à simples taxa sancionatória.

É importante observar que a adequação procedimental no sistema português é medida de exceção, admitida em situações específicas nas quais a utilização do procedimento previamente estabelecido comprometeria o direito material pleiteado.

Por outro lado, uma vez determinada a adequação procedimental pelo juízo, o procedimento adaptado deve ser seguido até a extinção do processo, sob pena de nulidade. Portanto, o procedimento adaptado é tão vinculativo quanto o previamente estabelecido em lei (GAJARDONI, 2008, p. 145).

Apesar dos esforços legislativos, observa-se que até a presente data não houve significativos avanços ou vantagens processuais no sistema processual português, já que faltou uma efetiva adesão dos operadores do direito. Por outro lado, as estatísticas demonstram que sob a ótica da celeridade processual, o novo regime procedimental não trouxe significativas alterações. Nas lições de Costa e Silva:

16. Os dados estatísticos oficiais que permitem extrair ilações quanto ao real impacto da consagração de um regime de gestão processual obrigatória sobre a duração das acções não são encorajadores. Os tempos de duração 
dos processos tramitados segundo o RPE, se comparados com aqueles que são os tempos de duração dos processos a que se aplicam formas de processo comum menos solenes, como seja o processo sumário de declaração, não são significativamente inferiores. Por outro lado, verifica-se uma tendência de alongamento da duração média dos processos tramitados em tribunais que aplicam o RPE.

A grande frustração que a leitura destes dados estatísticos pode esconder é a de se terem gorado as expectativas de quem imaginou que uma simplificação processual, acompanhada de um forte poder de gestão, seria uma espécie de panaceia para a morosidade da Justiça. A realidade mostra que assim não é. (2011, p. 140).

\section{FLEXIBILIZAÇÃO PROCEDIMENTAL NO PROJETO DO NOVO CÓDIGO DE PROCESSO CIVIL BRASILEIRO E NA VERSÃO FINAL DALEI N. ${ }^{\circ} 13.105 / 2015$}

A flexibilização do procedimento, intimamente relacionada ao princípio da adaptabilidade, nada mais é que a possibilidade de o juiz adotar, por iniciativa própria ou mediante provocação, o procedimento mais adequado à solução do conflito de acordo com as especificidades do direito material em litígio.

Esse modelo de gestão dos processos já foi adotado em outros ordenamentos jurídicos, como exposto no tópico anterior, e tem por escopo atribuir maior eficiência na prestação jurisdicional, com o uso racional do processo, de modo econômico e célere, de tal forma que garanta a maior participação das partes e uma maior autonomia do juiz na condução da marcha processual.

O projeto do Novo Código de Processo Civil brasileiro trouxe a previsão da flexibilização procedimental inicialmente no art. 107, V, segundo o qual o juiz dirigirá o processo conforme as disposições da lei, incumbindo-lhe "adequar as fases e os atos processuais às especificações do conflito, de modo a conferir maior efetividade à tutela do bem jurídico, respeitando sempre o contraditório e a ampla defesa".

$\mathrm{O}$ art. $151, \S 1^{\circ}$, do projeto, por sua vez, dispunha que:

Art. 151. Os atos e os termos processuais não dependem de forma determinada, senão quando a lei expressamente a exigir, considerando-se válidos os que, realizados de outro modo, lhe preencham a finalidade essencial. 
$\S 1^{\circ}$ Quando o procedimento ou os atos a serem realizados se revelarem inadequados às peculiaridades da causa, deverá o juiz, ouvidas as partes e observados o contraditório e a ampla defesa, promover o necessário ajuste.

O instituto da Flexibilização Procedimental, portanto, permitiria, na hipótese em que o procedimento previsto se mostrasse inadequado à tutela do bem jurídico pleiteado, a adequação do procedimento pelo juiz, às especificidades do caso concreto, para que o procedimento não se tornasse um obstáculo à consecução da finalidade do processo.

Verifica-se que a flexibilização procedimental seria medida de exceção, e estaria autorizada na hipótese de inexistência de procedimento ideal para a tutela de dada situação, caso em que competiria ao juiz [...] adequar o procedimento às peculiaridades da causa, criando ou mesclando ritos" (GAJARDONI, 2008, p. 170).

O juiz assim o fará, em caráter excepcional e fundamentadamente, quando constatar: (a) a inexistência de previsão legal adequada; (b) a inutilidade da regra formal avaliada no seu aspecto finalístico; ou, (c) a situação das partes litigantes, a justificar a variação ritual, a bem da igualdade material ou do consenso (GAJARDONI, 2008, p. 171).

Aplicada, portanto, apenas subsidiariamente ao trâmite processual, nas situações em que o procedimento regulado em lei for um óbice à tutela do bem jurídico pleiteado.

De imediato, as inovações sugeridas pelo projeto constante da Câmara dos Deputados dividiu a opinião dos operadores do direito entre os que aprovaram as novidades e os que viram com receio os dispositivos que permitiam a flexibilização judicial do procedimento (art. 107, V e 151, § $1^{\text {o }}$, do NCPC/Comissão).

Dentre as principais críticas elaboradas, afirmava-se que com a ampliação dos poderes do juiz na condução do procedimento e a possibilidade de flexibilização do procedimento caso a caso, não haveria o controle da atuação jurisdicional, principal fator para a preservação do modelo da rigidez formal, que garante a previsibilidade dos atos a serem praticados e a segurança jurídica dos litigantes (CABRAL, 2010, p. 150).

O grau de abstração do referido dispositivo ensejou preocupação pela ausência de "indicativo da forma e dos limites da flexibilização do procedimento" capaz de fomentar, na prática, “dúvidas e problemas pessoais" “ensejando uma indesejada insegurança jurídica que 
pode comprometer, em última análise, a própria aceitação dessa técnica" (CABRAL, 2010, p. 150).

Segundo Gajardoni (2015, p. 157) as críticas à referida inovação se devem, sobretudo, em razão de três principais fatores: i) o desconhecimento dos críticos do alcance da regra da flexibilização procedimental (princípio da adequação formal) e dos condicionamentos para sua aplicação; ii) à má compreensão do espírito do NCPC, no sentido de extinguir modelos procedimentais (sumário e especial) exatamente porque estaria permitida a calibração do rito no caso concreto; iii) à precária redação dos dispositivos que trataram do tema no texto do anteprojeto, os quais autorizaram a flexibilização através de cláusulas extremamente abertas, que não condicionavam a adequação formal a requisitos mínimos que pudessem garantir a previsibilidade e a segurança das partes.

Após uma enxurrada de críticas aos dispositivos relativos à flexibilização procedimental no anteprojeto, houve significativa alteração no substitutivo, e na atual redação a flexibilização procedimental se limita a duas principais hipóteses: o aumento de prazos e a inversão da produção dos meios de prova" (GAJARDONI, 2015, p. 160).

O Projeto do Novo Código de Processo Civil permite que o magistrado controle prazos, inverta a ordem probatória (art. 139, VI, Projeto), além de conferir às partes o direito de "estipular mudanças no procedimento para ajustá-lo às especificidades da causa" (art. 190, Projeto).

A regra da flexibilização procedimental foi mitigada no NCPC/Senado, e é admitida em apenas duas hipóteses específicas: i) ampliação de prazos e ii) alteração da ordem de produção provas. Ipsis literis:

Art. 118. O juiz dirigirá o processo conforme as disposições deste Código, incumbindo-lhe: [...].

V - dilatar os prazos processuais e alterar a ordem de produção dos meios de prova adequando-os às necessidades do conflito, de modo a conferir maior efetividade à tutela do bem jurídico.

Na versão definitiva da Lei n. ${ }^{\circ} 13.105 / 2015$, a flexibilização procedimental pelo juiz restou consolidada no art. 139, que assim dispõe:

Art. 139. O juiz dirigirá o processo conforme as disposições deste Código, incumbindo-lhe: 


\section{$[\ldots]$}

VI - dilatar os prazos processuais e alterar a ordem de produção dos meios de prova, adequando-os às necessidades do conflito de modo a conferir maior efetividade à tutela do direito;

De modo conservador e arraigado no sistema da legalidade das formas, optou o legislador brasileiro por uma alteração sutil, ao limitar a flexibilização procedimental à possibilidade de dilação dos prazos e à alteração da ordem de produção de provas.

Na prática, no afã de ter aprovada a versão final do texto do novo Código de Processo Civil pelo Senado Federal, houve significativa limitação da flexibilização procedimental, o que coloca em xeque a funcionalidade do instituto no sistema processual civil brasileiro, se analisado à luz do exaustivo regramento procedimental existente e de todas as suas especificidades.

\section{CONCLUSÃO}

A ideia de inserir no novo Código de Processo Civil brasileiro a flexibilização procedimental, um instituto alienígena e que de imediato se contrapõe ao sistema de legalidade das formas historicamente adotado pelo Brasil, gerou de imediato uma imensa desconfiança por parte dos operadores do direito, em especial por parte dos advogados, que questionaram a concentração de tantos poderes nas mãos dos magistrados.

Não significa que a possibilidade de adoção do instituto seja algo maléfico para o sistema processual, mas a sua adoção por si só não é suficiente para atender ao fim a que se propõe. Deve vir acompanhada de uma substancial alteração de todo o sistema de nulidades e de preclusões existente.

A questão é que o procedimento é visto como instrumento, ou seja, meio de se atingir a prestação jurisdicional, e não um fim em si mesmo. E em matéria de procedimentos, o Código de Processo Civil de 1973 não deixa a desejar. Existem inúmeros procedimentos especiais criados justamente para atender as especificidades do direito material envolvido, além do procedimento comum ordinário, que se mostra eficiente no que se refere à consecução de suas finalidades. 
A legislação procedimental brasileira no CPC/1973 é exaustiva, possui a disciplina de situações excepcionais nas quais se autoriza a flexibilização dos prazos, a supressão de fases processuais desde que não haja prejuízo ao interesse das partes, a dispensa de provas ou a alteração da ordem de produção destas, desde que determinada por decisão devidamente motivada.

O sistema processual substituído prevê, ainda, a inversão do ônus da prova, além da possibilidade de julgamento antecipado da lide, quando se tratar de matéria exclusivamente de direito, sem a necessidade de produção de outras provas.

No Brasil, somente há nulidade se houver efetivo prejuízo para às partes. Portanto, os procedimentos existentes são garantia de previsibilidade do sistema e fator de segurança jurídica, na medida em que uniformiza as práticas judiciais, permite o controle dos atos praticados, e evita surpresas e personalismos.

Cumpre destacar que dada a disciplina exaustiva existente no Código de Processo Civil de 1973, inúmeros procedimentos especiais sequer são utilizados, em virtude a abrangência do procedimento comum ordinário.

A flexibilização procedimental, no caso brasileiro, seria medida de exceção, apenas admitida em situações em que se verificasse na prática que o procedimento previsto para o caso fosse inadequada às peculiaridades da causa.

Ocorre que o sistema adotado pelo CPC/1973 já prevê uma série de situações excepcionais, que na prática atendem de maneira satisfatória às inúmeras demandas que perfazem a rotina do Poder Judiciário, sendo questionável a necessidade de se importar a flexibilização procedimental.

Esse questionamento ganha tintas mais fortes se consideradas as experiências alienígenas.

Em Portugal, a despeito da enorme reforma realizada, o que se verifica é a não adesão dos operadores do direito ao princípio da adequação formal. Como o mencionado princípio já foi criado como medida de exceção, muito provavelmente a não utilização se deve a desnecessidade prática da medida, tendo em vista todos os procedimentos previstos na legislação processual. 
A experiência norte-americana, por sua vez, evidencia que a busca pela celeridade e pela eficiência não pode ser atingida somente com a concentração de poderes de gestão processual nas mãos dos magistrados. O direito não se sustenta com meras estatísticas, e a produção em série é um risco para a qualidade da prestação jurisdicional.

O uso racional dos instrumentos processuais e dos recursos já é uma exigência do atual sistema processual brasileiro, que prevê uma série de sanções para práticas procrastinatórias, inclusive com a aplicação de multas.

O atual sistema procedimental não deixa a desejar em matéria de regulamentação. Do mesmo modo, não existem inúmeras situações excepcionais que justifiquem a inserção do dispositivo legal que autoriza a flexibilização no caso concreto.

A flexibilização procedimental não parece ser a resposta para solucionar os entraves existentes no sistema processual vigente, muito mais relacionados aos fatores humanos que normativos. Da mesma forma, não é possível vislumbrar nos procedimentos existentes a causa da tão criticada morosidade na prestação jurisdicional, na medida em que o magistrado já é autorizado pelo sistema vigente a apenas praticar os atos processuais e deferir as provas que se demonstrem realmente necessários.

Um possível caminho para atingir as desejadas celeridade e eficiência do sistema processual está em aparelhar adequadamente o Poder Judiciário, oferecer treinamento e qualificação para os servidores, fixar metas de resultados, e, até mesmo, estabelecer um prazo médio de duração dos processos de acordo com a complexidade da matéria envolvida. Medidas gerencias, atreladas à aplicação efetiva da legislação existente, e, quem sabe, associada a uma mudança de mentalidade dos operadores do direito, com a visão dos litigantes como cooperadores na prestação jurisdicional, seria um instrumento de racionalização do processo muito mais eficiente que a mera alteração legislativa.

A atual redação do art. 139 do Código de Processo Civil sem dúvida alguma esvaziou o instituto da flexibilização procedimental, sendo questionável a necessidade do dispositivo legal em análise, na medida em que na prática, não havendo prejuízo, já era possível flexibilizar prazos e alterar a ordem de produção de provas, nas hipóteses previstas em lei, e desde que por decisão fundamentada, sendo garantido o contraditório. 


\section{REFERÊNCIAS}

ALMEIDA, Diogo A. Rezende de. O case management inglês: um sistema maduro. REDP. Rio de Janeiro: Ano 5. Volume VII. P. 288/338. JAN/JUN 2011. ISSN 1982-7636. Disponível em:<http://www.redp.com.br/arquivos/redp_7a_edicao.pdf> Acesso em 03.12.2015.

AMENDOEIRA JUNIOR, Sidney. Poderes do juiz e tutela jurisdicional: a utilização racional dos poderes do juiz como forma de obtenção da tutela jurisdicional efetiva, justa e tempestiva. São Paulo: Atlas, 2006.

BARBOSA MOREIRA, José Carlos. Convenções das partes sobre matéria processual. In: MOREIRA, José Carlos Barbosa (Org.) Temas de Direito Processual: Terceira Série. São Paulo Saraiva, 1984. p. 87-98.

Temas de direito processual: nona série. São Paulo: Saraiva, 2007.

Uma novidade: o Código de Processo Civil inglês. Revista de Processo, São Paulo, Revista dos Tribunais, ano 25, n. 99, p. 4-83, jul./set. 2000.

BEDAQUE, José Roberto dos Santos. Direito e processo: influência do direito material sobre o processo. São Paulo: Malheiros, 1995.

Poderes instrutórios do juiz. 7. ed. ver., atual. E ampl. São Paulo: RT, 2013.

BONICIO, Marcelo José Magalhães. Proporcionalidade e processo: a garantia constitucional da proporcionalidade, a legitimação do processo civil e o controle das decisões judiciais. São Paulo: Atlas, 2008. - (Coleção Atlas de Processo Civil/ coordenação Carlos Alberto Carmona).

CABRAL, Antônio do Passo. Nulidades no processo moderno: contraditório, proteção da confiança e validade prima facie dos atos processuais. Rio de Janeiro: Forense, 2009.

CABRAL, Trícia Navarro Xavier.Flexibilização procedimental. Revista Eletrônica de Direito Processual, Rio de Janeiro. Ano 4. Volume VI, p. 135/164.Jul/Dez. 2010. ISSN 19827636. Disponível em: <www.revistaprocessual.com>. Acesso em: 05 fev. 2015.

CAMARA E SILVA, Erick Simões da.A dúvida objetiva como único requisito para a aplicação do princípio da fungibilidade dos meios no processo civil: posicionamento do 
Supremo Tribunal Federal. Revista de Processo, São Paulo, Revista dos Tribunais, Ano 35, n. 181 , p. 273-296, mar./2010.

COSTA E SILVA, Paula. Legalidade das formas de processo egestão processual ou as duas faces de Janus.in Revista de Legislação Legislativa - Brasilia.- A.48, no 100 (Abr.Jun.2011), p. 137- 149.

GAJARDONI, Fernando da Fonseca. Flexibilização procedimental: um novo enfoque para o estudo do procedimento em matéria processual, de acordo com as recentes reformas do CPC. São Paulo: Atlas, 2008. - (Coleção Atlas de Processo Civil/ coordenação Carlos Alberto Carmona).

Flexibilização procedimental: razoabilidade ou excesso de poder do juiz?In: ROSSI, Fernando [et al.] (coord.). O futuro do processo civil no Brasil: uma análise crítica do projeto do Novo CPC. Belo Horizonte: Fórum, 2011, p. 693.

Procedimentos, déficit procedimental e flexibilização procedimental no novo CPC. Revista Eletrônica de Direito Processual, Rio de Janeiro. Ano 48. N. ${ }^{\circ}$ 190, Volume VI, p. 135/164. Abr/Jun. 2011. ISSN 1982-7636. Disponível em: 〈www.revistaprocessual.com>. Acesso em: 05 fev. 2015.

O princípio da adequação formal no Direito Processual Civil Português. Revista do Instituto do Direito Brasileiro, v. 1, p. 665-686, 2012.

GRECO, Leonardo. Os atos de disposição processual: primeiras reflexões. Revista Eletrônica de Direito Processual, out./dez. 2007. Disponível em: <www.revistaprocessual.com>. Acesso em: 08 fev. 2015.

MENDONÇA, Luís Correia de. Processo civil líquido e garantias (o regime processual experimental português). Revista de Processo, São Paulo, Revista dos Tribunais, ano 34, n.170, p. 215 -250, dez./ 2009. p. 234.

MOREIRA PINTO, Junior Alexandre. O regime processual experimental português. Revista de Processo, São Paulo, Revista dos Tribunais, ano 32. n. 148. p. 169-180, jun. 2007. 
MOREIRA. Rui. Os princípios estruturantes do processo civil português e o projecto de uma nova reforma do processo civil. Tribunal da Relação do Porto. Disponível em $<$ http://www.trp.pt/ficheiros/estudos/coloquiocpc_ruimoreira_osprincipiosestruturantesdoproc essocivilportugues.pdf> Acesso em 05 Jan. de 2015.

NUNES, Dierle. Novo enfoque para as tutelas diferenciadas no Brasil? Diferenciação procedimental a partir da diversidade de litigiosidade. Revista de Processo, São Paulo, Revista dos Tribunais, ano 35, n. 184, p. 109-140, junho/2010.

PASSOS, J. J. Calmon de. Instrumentalidade do processo e devido processo legal. Revista Diálogo Jurídico, Salvador, CAJ - Centro de Atualização Jurídica, v. 1, nº 1, 2001. (ABNT: NBR-6023/2000): Disponível em: <http://www.direitopublico.com.br>. Acesso em: 15 de jan. 2015.

RESNIK, Judith. Managerial Judges. Harvard Law Review, v. 96, n. 2, p. 374-448, Dec.1982. Disponível em: 〈http://www.jstor.org/pss/1340797〉. Acesso em: 14 jan. 2015.

TARUFFO, Michele. Investigación judicial y producción de prueba por las partes. Traducción de Juan Andrés Varas Braun. Revista de Derecho, Valdivia, v. 15, n. 2, p. 205 213, dic. 2003.

TEIXEIRA, Guilherme de Freire Barros. Teoria do princípio da fungibilidade. São Paulo: Revista dos Tribunais, 2008. (Coleção temas atuais de direito processual civil; v. 13).

TAVARES, Luiz Marcelo Cabral. Perspectivas da flexibilização procedimental na experiência brasileira em face do substitutivo do senador Valter Pereira ao projeto de lei no senadon. 166, de 2010. Revista Eletrônica de Direito Processual Civil da UERJ. ISSN 1982-7636. Ano 5. Volume VII, 2011. Rio de Janeiro. Disponível em www.redp.com.br. Acesso em: 10 Jan. 2015.

WAMBIER, Luiz Rodrigues. A flexibilidade procedimental como instrumento aliado da celeridade e da efetividade do processo. Revista Eletrônica Migalhas. ISSN 1983-392X. 2013. Disponível em http://www.migalhas.com.br/dePeso/16,MI184713,21048A+flexibilidade+procedimental+como+instrumento+aliado+da+celeridade+e Acesso em jan. de 2015 . 